\title{
Long-term survival of dogs after experimental pulmonary reimplantation and staged contralateral pneumonectomy
}

\author{
P. MCN . HILL AND K. M. SHAW \\ From the Department of Experimental Surgery, Trinity College, Dublin
}

\begin{abstract}
Sixteen dogs which survived left pulmonary reimplantation were subjected to staged contralateral pneumonectomy. Complete excision of the right lung was achieved in nine of these animals. There were three long-term survivors, of which two lived for more than three years on the single reimplanted lung. Stenosis of the pulmonary veins at the level of the atrial anastomosis was the commonest post-mortem finding. In the first week after reimplantation, the ventilation and oxygen uptake of the reimplanted lung invariably fell to low levels. These usually rose slowly but to a variable extent over the next six to eight weeks, after which there was little further improvement while the normal lung remained intact. In all three long-term survivors the ventilation and oxygen uptake of the reimplanted lung were more than doubled after contralateral pneumonectomy; the rise in oxygen uptake was less and occurred later than the rise in ventilation. Pulmonary hypertension and pulmonary oedema did not occur except in association with organic obstruction to the pulmonary venous drainage.
\end{abstract}

Survival of experimental animals on a single reimplanted lung is uncommon. The initial operation of pulmonary reimplantation carries a high mortality rate (Blumenstock and Kahn, 1961; Linberg, Demetriades, Armstrong, and Konsuwan, 1961 ; Yeh, Ellison, and Ellison, 1962 ; Alican and Hardy, 1963 ; Nigro, Evans, Benfield, Gaco, Fry, and Adams, 1963 ; Haglin, Telander, Muzzall, Kiser, and Strobel, 1963 ; Shaw and Burton, 1964 ; Borrie and Lichter, 1964 ; Davies, Rosser, and West, 1965 ; Guilmet, Brunet, Krakora, Leiva, and Weiss, 1965) and in dogs subsequent contralateral pneumonectomy in one stage has been almost uniformly fatal (Yeh et al., 1962 ; Nigro, Reimann, Fry, Mock, and Adams, 1961 ; Nigro et al., 1963 ; Alican and Hardy, 1963 ; Hardy, Eraslan, Dalton, Alican, and Turner, 1963 ; Haglin et al., 1963 ; Bücherl, Nasseri, and von Prondzynski, 1964; Duvoisin, Fowler, Spencer Payne, and Ellis, 1964).

Nigro and his colleagues $(1961,1963)$ were the first to suggest that staged ablation of the opposite lung might increase the chances of an animal surviving on a single reimplanted lung. They reported long-term survival in 5 of 16 dogs successively subjected to right lung reimplantation, left upper lobectomy, and cauterization of the left lower lobe bronchus with silver nitrate. The technique effec=्ञ tively confines gaseous exchanges to the reimplant but it leaves the nerve supply (and possibly theo vasculature) of the left lower lobe intact. A staged but complete excision of the opposite lung, there-0 fore, is a more rigorous test of the function of $\mathrm{B}$. the pulmonary autograft. By resecting the righ $\bar{B}$ lung in two or three operations after left pulmo nary reimplantation we have achieved long-termo survival in 3 of 16 dogs.

\section{MATERIAL AND METHODS}

Mongrel dogs of about $20 \mathrm{~kg}$. weight had the lef? lung reimplanted by a standard method (Neptuneç Redondo, and Bailey, 1953; Neptune, Weller, an Bailey, 1953). Sixteen survivors were submitted to staged excision of the right lung, begun at various్ times between 12 days and 8 months after reimplanta tion. Dogs which survived the first stage had a second -and sometimes a third-operation at intervals of two to four weeks to complete the right pneumonec tomy. The choice and number of lobes removed aP each operation depended on the state of the re@ implant's function as determined beforehand be bronchospirometry.

Periodic assessments of the function of tho reimplanted lung were made by clinical and radio 
graphic examination, bronchoscopy, simultaneous differential bronchospirometry, and cardiac catheterization. Bronchospirometry was carried out using a catheter developed in this laboratory ${ }^{1}$ and a Lode D 52 bronchospirograph ${ }^{2}$ modified for use with dogs. Intravascular and intracardiac pressures were recorded either with a Statham P23 Db type strain gauge connected to a Siemens Ediswan pen oscillograph and amplifiers or with the Elema-Schonander EMT 34 pressure transducer and EMT 31 electromanometer connected to a Mingograph 81 ink-jet direct writer. Pressures were recorded with the animal anaesthetized and supine; the level of the dog's spine was taken as the zero point of reference for pressure measurements. Mean pressures were recorded electronically. The cardiac output was estimated by the direct Fick method.

A necropsy was carried out in each dog.

\section{RESULTS}

The data for all 16 dogs are summarized in the Table.

MORTALITY Seven animals died during or shortly after the initial stages of the contralateral pneumonectomy. Complete excision of the right lung was achieved in the remaining nine dogs. Of these, three died within a few hours of the final operation, three lived for short periods of 6,8 , and 12 days respectively, and three were long-term survivors. Two of the long-term survivors lived for more than three years on the single reimplanted lung.

${ }^{1}$ Hill and Shaw (1968)

${ }^{2}$ Lode Instrumenten, Groningen, Holland
The commonest post-mortem finding was stenosis or thrombosis of the pulmonary veins at the level of the atrial anastomosis. The commonest cause of death was pulmonary oedema.

CLINICAL OBSERVATIONS Before staged right pneumonectomy, all 16 dogs were in good health and could run several hundred yards on the flat without distress. One month after completion of the right pneumonectomy, all three long-term survivors had recovered sufficiently to tolerate vigorous exercise.

CHEST RADIOGRAPHS In the first week after reimplantation, chest radiographs showed a variable degree of diffuse mottling over almost the whole of the left lung field. This tended to be more dense over the base and mid-zone; it was attributed to congestion of the reimplant and was seen to clear gradually over the next few weeks. Following contralateral pneumonectomy all three long-term survivors showed a similar picture of increased density with rib retraction on the right and a moderate shift of the mediastinum to the same side. Ten days after the final operation a chest film in one of these dogs (No. 58) showed a small pneumothorax which cleared spontaneously over the next few days.

BRONCHOSPIROMETRY During the first week after reimplantation there was a marked fall in the oxygen uptake and ventilation of the reimplanted

T A B L E

SUMMARY OF DATA ON 16 DOGS SUBJECTED TO LEFT PULMONARY REIMPLANTATION AND STAGED CONTRALATERAL PNEUMONECTOMY

\begin{tabular}{|c|c|c|c|c|}
\hline $\begin{array}{l}\text { Dog } \\
\text { No. }\end{array}$ & $\underset{0}{\mathrm{~L}} \underset{\mathbf{1}}{\mathbf{V}} \mathrm{O}_{2}$ & \begin{tabular}{l}
\multicolumn{1}{c}{ Interval between } \\
Reimplantation and \\
First Stage Contralareral \\
Pneumonectomy (days)
\end{tabular} & $\begin{array}{l}\text { Survival after } \\
\text { Completion of } \\
\text { Contralateral } \\
\text { Pneumonectomy }\end{array}$ & $\begin{array}{l}\text { Cause of Death } \\
\text { and Principal Post-mortem Findings }\end{array}$ \\
\hline $\begin{array}{l}58 \\
60\end{array}$ & $\begin{array}{r}67 \\
140\end{array}$ & $\begin{array}{r}49 \\
119\end{array}$ & $\begin{array}{l}3 \text { years } 2 \text { days } \\
\text { Not completed }\end{array}$ & $\begin{array}{l}\text { Asphyxia following tracheostomy. Left upper lobe vein stenosed } \\
\text { Infarction of right middle lobe secondary to pulmonary venous throm- } \\
\text { bosis. Stenosis of left upper and middle lobe veins }\end{array}$ \\
\hline $\begin{array}{l}61 \\
62 \\
72 \\
74 \\
98 \\
99\end{array}$ & $\begin{array}{r}86 \\
86 \\
44 \\
50 \\
67 \\
7\end{array}$ & $\begin{array}{r}45 \\
56 \\
74 \\
56 \\
237 \\
45\end{array}$ & $\begin{array}{l}3 \text { years } 15 \text { days } \\
\text { Not completed } \\
12 \text { days } \\
\text { Not completed } \\
0 \text { days } \\
\text { Not completed }\end{array}$ & $\begin{array}{l}\text { Asphyxia following tracheostomy. Left upper lobe vein stenosed } \\
\text { Pulmonary oedema } \\
\text { Pneumonia. Stenosis of left upper and middle lobe veins } \\
\text { Pulmonary oedema with stenosis of all left pulmonary veins } \\
\text { Cardiac arrest immediately after completion of right pneumonectomy } \\
\text { Sacrificed after first stage right pneumonectomy. Almost complete }\end{array}$ \\
\hline 131 & 67 & 42 & 8 days & $\begin{array}{l}\text { Profuse haemoptysis due to pulmonary infarction superimposed on } \\
\text { stenosis of upper and middle lobe veins }\end{array}$ \\
\hline $\begin{array}{l}138 \\
143\end{array}$ & 25 & $\begin{array}{l}11 \\
56\end{array}$ & $\begin{array}{l}\text { Not completed } \\
6 \text { days }\end{array}$ & $\begin{array}{l}\text { Pulmonary oedema and stenosis of all left pulmonary veins } \\
\text { Cardiac arrest after re-opening chest for pneumothorax and pleural } \\
\text { effusion. Stenosis of left uppen and middle lobe veins }\end{array}$ \\
\hline $\begin{array}{l}146 \\
147 \\
160 \\
166 \\
186\end{array}$ & $\begin{array}{l}- \\
58 \\
50 \\
29\end{array}$ & $\begin{array}{r}39 \\
42 \\
63 \\
113 \\
56\end{array}$ & $\begin{array}{l}\text { Not completed } \\
\text { Not completed } \\
35 \text { days } \\
0 \text { days } \\
0 \text { days }\end{array}$ & $\begin{array}{l}\text { Pneumothorax from leaking bronchial stump } \\
\text { Gastro-enteritis. Stenosis of left upper and middle lobe veins } \\
\text { Sacrificed } \\
\text { Anaesthetic death. Stenosis of left upper lobe veins } \\
\text { Pulmonary oedema. Severe stenosis of all left pulmonary veins }\end{array}$ \\
\hline
\end{tabular}

${ }^{1} \mathrm{~L} \quad \mathrm{VO}_{2} \%=$ maximum value for oxygen consumption of left lung, recorded after reimplantation but before first stage of contralateral pneumonectomy, expressed as a percentage of normal. The maximum value for the oxygen consumption of the left lung recorded before reimplantation is taken as the normal value. 

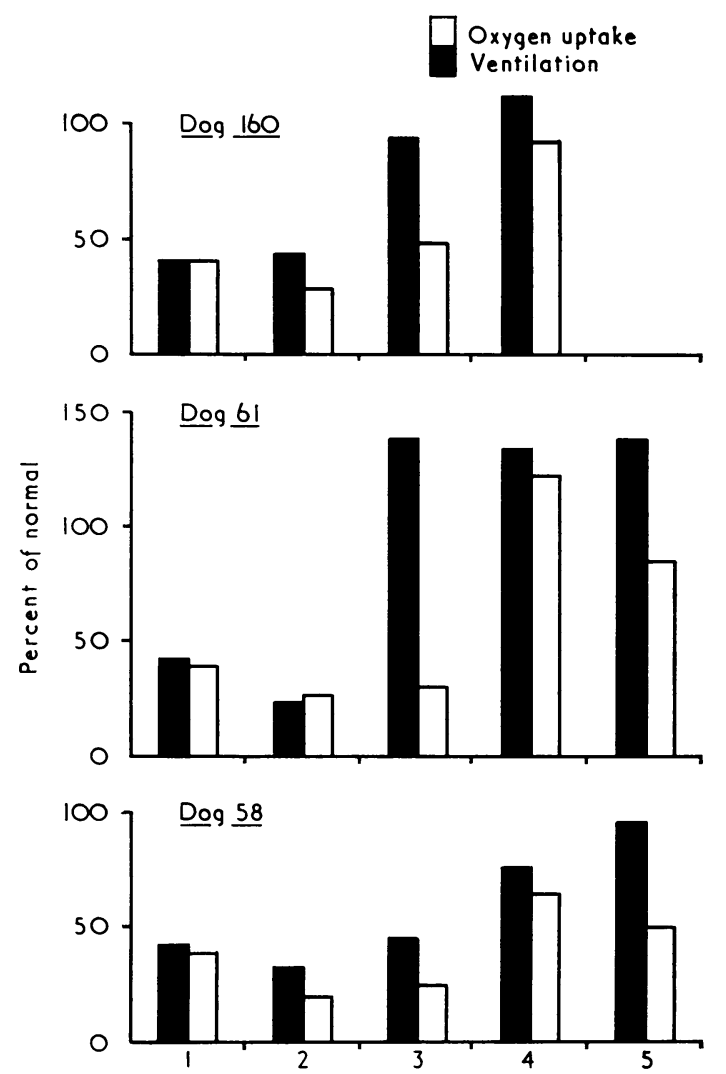

FIG. 1. Changes in the ventilation and oxygen uptake of the reimplanted lung in long-term survivors of pulmonary reimplantation and contralateral pneumonectomy. $100 \%$ of normal $=$ sum of values for right and left lungs before reimplantation; (1) before reimplantation; (2) after reimplantation; (3) after first-stage right pneumonectomy; (4) after second-stage right pneumonectomy; (5) 3 years after reimplantation.

lung. A gradual rise followed, which usually reached a plateau about six to eight weeks after the operation. The level of this plateau varied from one dog to another. Plateau levels for ventilation frequently equalled or exceeded preoperative levels ; except in one dog (No. 60), those for oxygen uptake were always less than the preoperative levels.

In all three long-term survivors the reimplanted lung responded to the increasing respiratory loads imposed by staged contralateral pneumonectomy by further increases in ventilation and oxygen uptake to values above the plateau levels previously reached. These findings are illustrated diagramatically in Figure 1.
PULMONARY ARTERIAL PRESSURES Pulmonary ar- $\stackrel{\vec{\rho}}{\stackrel{9}{9}}$ terial pressures remained at normal levels in all 으 three long-term survivors up to the time of death. In one animal (No. 160) pressures were monitored $\frac{\text { के }}{\sigma}$ during both stages of the contralateral pneumo- $\mathbb{Q}$ nectomy. Figure 2 shows a record made during the first stage ; the application of a clamp to the right $\vec{\circ}$

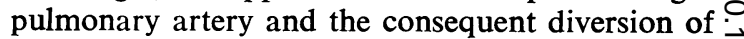
the entire cardiac output through the reimplanted $\vec{\omega}$ lung had no effect on the pressure recorded in the main pulmonary artery. A similar result was ob- $\vec{x}$ tained during the second stage.

In contrast, Fig. 3 shows the results of the same procedure in another animal (No. 186) with severe pulmonary venous stenosis which died immedi- $\infty$ ately after completion of the right pneumonec- $\frac{\text { ? }}{5}$ tomy. The severity of the obstruction to blood flow through the reimplanted lung is shown by the $\complement$ fall in systemic arterial pressure to zero that accompanies the steep rise in main pulmonary $\vec{\bullet}$ artery pressure.

NECROPSY RESULTS The causes of death for all 16 dogs are given in the Table. Of the long-term survivors, dog 160 was sacrificed 35 days after completion of the contralateral pneumonectomy. $\frac{\mathbb{D}}{\mathbb{D}}$ At necropsy there was a satisfactory technical result with no stenosis of the bronchial or vascular suture lines. Macroscopically, the reimplanted lung appeared normal and was well expanded. Microscopically, however, there was a generalized hypertrophy of smooth muscle (Fig. 4).

Both three-year survivors died within 10 days of tracheostomies carried out with a view to further respiratory studies during exercise. In each case the cause of death was asphyxia from blockage of the tracheostomy and airways by inspissated secretions. The vein draining the left upper lobe was stenosed in both dogs, being completely occluded in $\operatorname{dog} 58$ but remaining narrowly patent in $\operatorname{dog}$ 61 (Fig. 5).

\section{DISCUSSION}

The object of these studies of pulmonary reimplantation is the development of a satisfactory $\stackrel{?}{+}$ technique for transplantation of the lung, an 0 object which demands investigation of the purely technical as opposed to the immunological con- $\stackrel{\mathbb{D}}{\Omega}$ sequences of the procedure. A technique can only $\stackrel{\mathbb{Q}}{\varnothing}$ be judged satisfactory if it regularly produces functioning pulmonary reimplants. Survival with the opposite normal lung intact is no index of $\frac{0}{0}$ success, for dogs can survive in good health for 


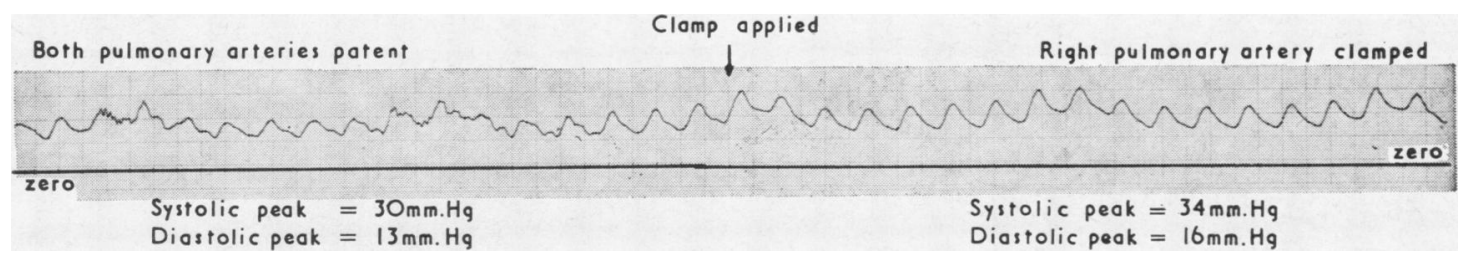

FIG. 2. Dog 160. Tracing of main pulmonary artery pressure recorded during first stage of right pneumonectomy. A clamp was applied to the right pulmonary artery at the time indicated by the arrow. There was no marked change in pressure. Speed, $25 \mathrm{~mm}$. per second. Calibration, $10 \mathrm{~mm}$. $\mathrm{Hg}$ pressure $=5 \mathrm{~mm}$. deflection on paper.

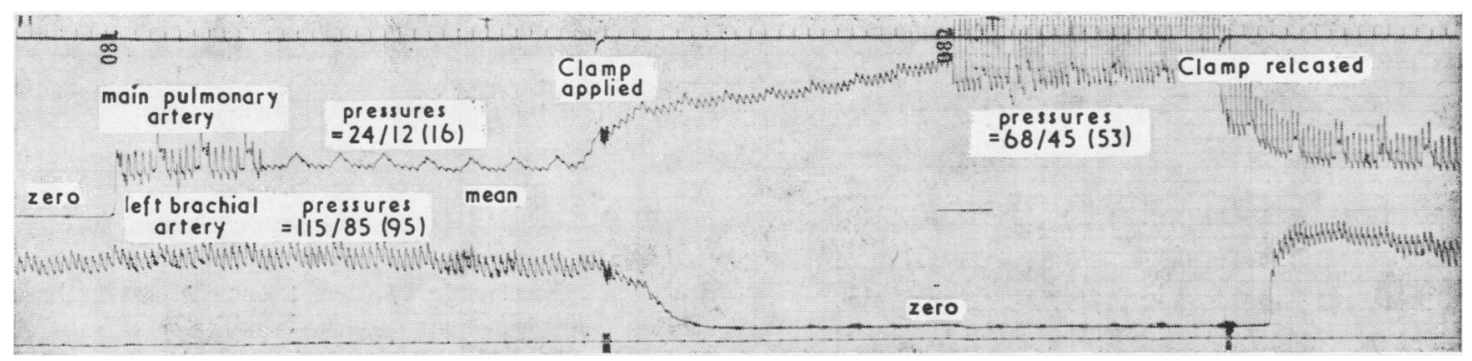

FIG. 3. Dog 186. Tracing of main pulmonary artery and brachial artery recorded during first stage of right pneumonectomy. A clamp was applied to the right pulmonary artery at the time indicated. There was an immediate rise in pulmonary artery pressures to near systemic levels with a concomitant fall in brachial artery pressure to zero. Speed, $5 \mathrm{~mm}$. per second; calibration, pulmonary artery trace, $10 \mathrm{~mm} . \mathrm{Hg}$ pressure $=10 \mathrm{~mm}$. deflection on paper; brachial artery trace, $10 \mathrm{~mm}$. $\mathrm{Hg}$ pressure $=2.5 \mathrm{~mm}$. deflection on paper.

long periods on a single lobe of the right lung (Shaw and Burton, 1964). The crucial test is the pragmatic one of the capacity of the reimplant to support life unaided.

In this series the principal cause of failure was stenosis or thrombosis of the pulmonary veins at the level of the atrial anastomosis. The high incidence of this complication after reimplantation is well established (Yeh et al., 1962; Alican and Hardy, 1963 ; Nigro et al., 1963 ; Haglin et al., 1963 ; Guilmet et al., 1965 ; Davies et al., 1965). The cephalad and middle veins were more frequently affected than the caudad, stenosis of the former being present in 12 of the 16 dogs. This finding is probably related to the small calibre of these vessels as compared with the large (and usually single) caudad vein. The latter was affected in only four dogs and only in association with stenosis of the other veins draining the reimplant.

A number of authors have commented on the occurrence of diminished ventilation and oxygen uptake, pulmonary hypertension, and pulmonary oedema after reimplantation and contralateral surgery (Yeh et al., 1962; Alican and Hardy, 1963 ; Nigro et al., 1963, 1964 ; Reemtsma, Rogers, Lucas, Schmidt, and Davis, 1963 ; Haglin et al., 1963 ; Amirana, Rohman, Oka,
Kikkawa, Gueft, and State, 1964 ; Weiss, Toty, and Guilmet, 1966). Haglin et al. (1963) noted that the upper lobe of the reimplanted canine lung was not as well expanded as the lower lobe. All these changes were observed in our series but were constantly related to the presence of pulmonary venous stenosis. Pulmonary oedema without pulmonary venous stenosis occurred in only one dog (No. 62) ; we are unable to explain this.

In our hands, thrombosis and stenosis of the pulmonary veins have continued to occur after reimplantation of the dog lung in spite of whole body heparinization at the time of operation and various modifications of surgical technique. They have occurred even when the atrial anastomosis has been judged completely satisfactory at the conclusion of the procedure. This is in contrast with the experience of Davies and his colleagues (1965) who, working with sheep, found 'no important obstruction by thrombus except as a complication of severe surgical narrowing'. Benfield and Coon (1967) have suggested that the problem is peculiar to the dog. Haglin et al. (1963), who reported survival on a single reimplanted lung in 6 of 8 baboons, found pulmonary venous thrombosis after reimplantation in only 1 of 20 of these primates. 


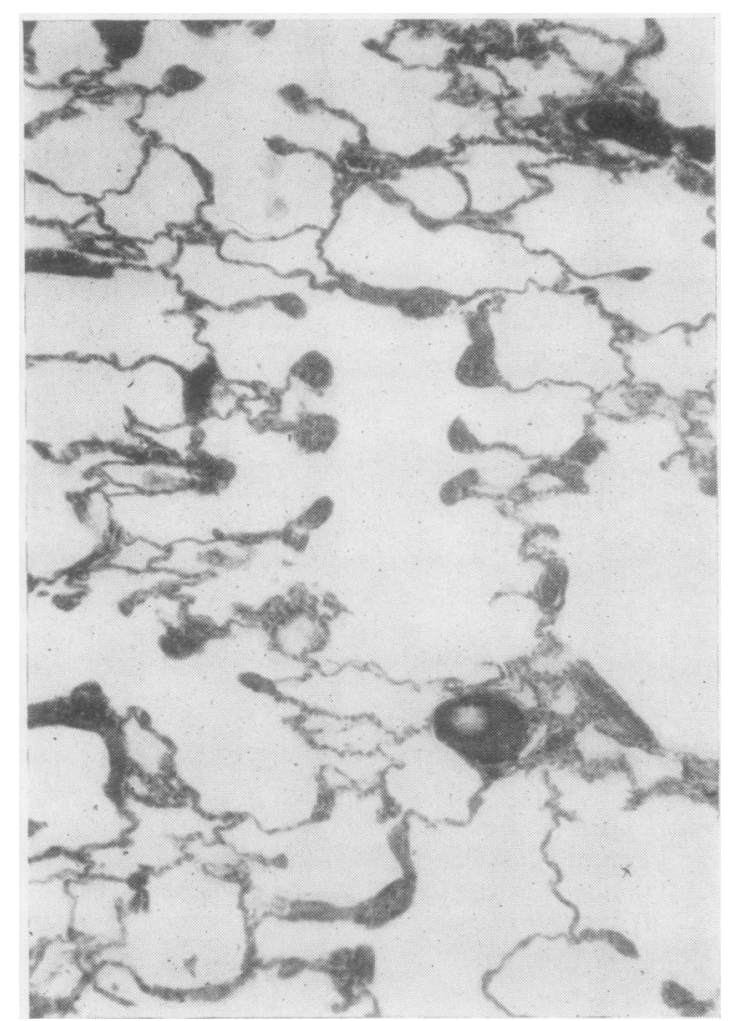

FIG. 4. Necropsy from dog 160 showing hypertrophy of infundibular smooth muscle. $H$. and $E . \quad \times 63$.
We have confirmed the correlation between a diminished oxygen uptake and the presence of structural defects in the autograft that has been observed by others (Duvoisin et al., 1964), but have found it of limited value in predicting the results of contralateral surgery. Long-term survival on a single reimplanted lung is unlikely if the oxygen uptake is less than $60 \%$ of normal, but values in excess of this do not necessarily indicate a successful outcome to staged excision of the opposite lung (see Table).

Assessment of the true functional capacity of the reimplanted lung is difficult. Bronchospirometry, like most other tests of lung function in animals, is normally carried out under anaesthesia and at near basal levels of metabolism. The measured oxygen uptake of the reimplant therefore represents only a fraction of its potential function and leaves a reserve of undetermined extent. The resulting problem is manifest in the dramatic rise in ventilation and oxygen uptake which followed contralateral pneumonectomy in all three long-term survivors. Does this represent a real improvement in the function of the autograft or simply a reduction in its respiratory reserve? It is possible that after contralateral pneumonectomy more forceful respiratory efforts and an enhanced blood flow may bring about the re-expansion of previously collapsed alveoli and the reopening of previously obstructed vascular channels. This might explain the phenomenon of the 'lazy lung' syndrome described by Shaw and

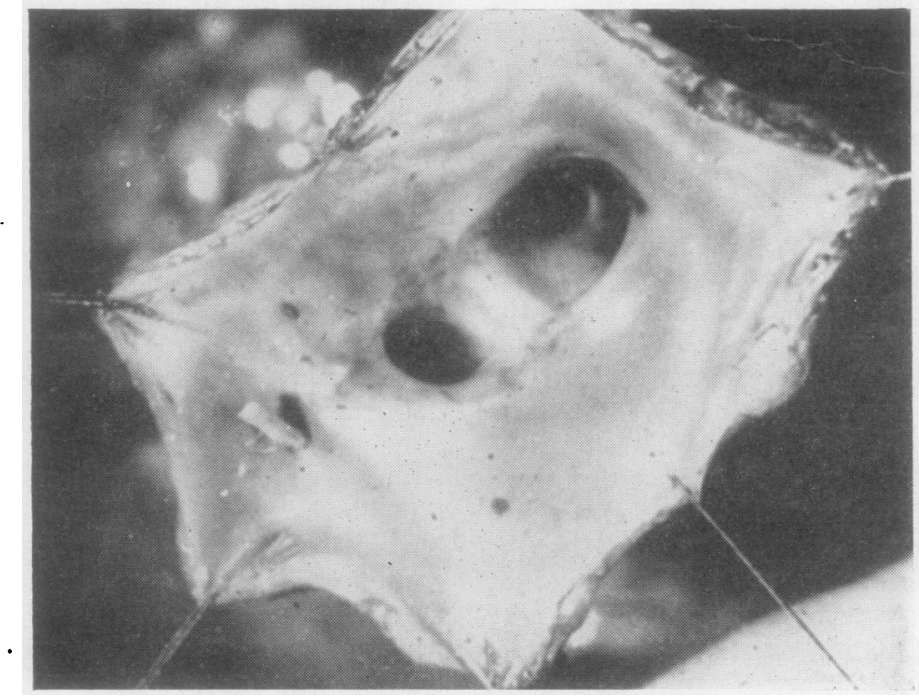

FIG. 5. Ostia of left pulmonary veins in dog 61 viewed from within the opened left atrium. The middle and lower lobe veins are patent; a match-stick has been placed in the narrowed upper lobe vein. 
Burton (1964). Proof of this thesis, however, demands measurement of the ventilation and oxygen uptake of the reimplant under conditions of vigorous exercise.

The practical difficulties involved in the differential measurement of lung function during exercise are considerable. Tracheostomy appears to be an essential preliminary for bronchospirometry in the unanaesthetized animal, but this proved fatal in both three-year survivors. Faber and his associates (Faber, Pedreira, Pevsner, and Beattie, 1965) have commented on the difficulty in clearing secretions experienced by animals which have undergone total pulmonary denervation. This was not a major problem in the three long-term survivors we have described, but ineffective coughing combined with the further physiological insult of tracheostomy may explain the two fatalities.

Finally, while obstruction to the pulmonary venous drainage is probably the major cause of failure to obtain satisfactorily functioning reimplants, other factors must contribute. The prolonged survival of two of our dogs on a single reimplanted lung with stenosis of the left upper lobe vein illustrates that the complication is not invariably fatal.

\section{CONCLUSIONS}

Long-term survival on the single reimplanted lung is possible.

Thrombosis and stenosis of the pulmonary veins at the level of the atrial anastomosis is the principal cause of failure in dogs.

Tracheostomy is not tolerated by dogs surviving on a single reimplanted lung.

\section{REFERENCES}

Alican, F., and Hardy, J. D. (1963). Lung reimplantation. Effect on respiratory pattern and function. J. Amer. med Ass., 183, 849.
Amirana, M. T., Rohman, M., Oka, M., Kikkawa, Y., Gueft, B., and State, D. (1964). Functional and pathologic changes in the reimplanted lung. Surg. Forum, 15, 177.

Benfield, J. R., and Coon, R. (1967). The role of the left atrial anastomosis in pulmonary reimplantation. J. thorac. cardiovasc. Surg., 53, 676.

Blumenstock, D. A., and Kahn, D. R. (1961). Reimplantation and transplantation of the canine lung. J. surg. Res., $1,40$.

Borrie, J., and Lichter, I. (1964). Lung reimplantation: technical problems. Thorax, 19, 383.

Bücherl, E. S., Nasseri, M., and von Prondzynski, B. (1964). Lung function studies after homotransplantation, autotransplantation, denervation of the left lung, and ligature of the right pulmonary artery. J. thorac. cardiovasc. Surg., 47, 455.

Davies, L. G., Rosser, T. H. L., and West, L. R. (1965). Autotransplantation of the lung in sheep. Thorax, 20, 481.

Duvoisin, G. E., Fowler, W. S., Spencer Payne, W., and Ellis, F. H. (1964). Reimplantation of the dog lung with survival after contralateral pneumonectomy. Surg. Forum, 15, 173.

Faber, L. P., Pedreira, A. L. S., Pevsner, P. H., and Beattie, E. J. (1965). The immediate and long-term physiologic function of bilateral reimplanted lungs. J. thorac. cardiovasc. Surg., 50, 761.

Guilmet, D., Brunet, A., Krakora, P., Leiva, A., and Weiss, M. (1965) Contribution expérimentale á l'étude de la transplantation pulmonaire. 1. La réimplantation du poumon chez le chientechnique: premiers resultats. Ann. Chir. Thorac. Cardiovasc., 4, 306 (Ann. Chir., 19, 558).

Haglin, J., Telander, R. L., Muzzall, R. E., Kiser, J. C., and Strobel, C. J. (1963). Comparison of lung autotransplantation in the primate and dog. Surg. Forum, 14, 196.

Hardy, J. D., Eraslan, S., Dalton, M. L., Alican, F., and Turner, M. D. (1963). Re-implantation and homotransplantation of the lung: laboratory studies and clinical potential. Ann. Surg., 157, 707.

Hill, P., and Shaw, K. M. (1968). A technique for differential bronchospirometry in dogs. In preparation.

Linberg, E. J., Demetriades, A., Armstrong, B. W., and Konsuwan, N. (1961). Lung reimplantation in the dog. J. Amer. med. Ass., 178, 486.

Neptune, W. B., Redondo, H., and Bailey, C. P. (1953). Experimental lung transplantation. Surg. Forum, 1952, 3, 379.

-Weller, R., and Bailey, C. P. (1953). Experimental lung transplantation. J. thorac. Surg., 26, 275.

Nigro, S. L., Evans, R. H., Benfield, J. R., Gago, O., Fry, W. A., and Adams, W. E. (1963). Physiologic alterations of cardiopulmonary function in dogs, living one and one-half years on only a reimplanted right lung. J. thorac. cardiovasc. Surg., 46, 598.

- Reimann, A. F., Fry, W. A., Mock, L. F., and Adams, W. E. (1961). Alterations in cardio-pulmonary physiology following autotransplantation of the lung. Surg. Forum, 12, 56 .

Reemtsma, K., Rogers, R. E., Lucas, J. F., Schmidt, F. E., and Davis F. H. (1963). Studies of pulmonary function in transplantation of the canine lung. J. thorac. cardiovasc. Surg., 46, 589.

Shaw, K. M., and Burton, N. A. (1964). Experimental pulmonary reimplantation. Thorax, 19, 180 .

Weiss, M., Toty, L., and Guilmet, D. (1966). Contribution expérimentale a l'étude de la transplantation pulmonaire. Ann. Chir. Thorac. Cardiovasc., 5, p. C.497, C.T. 189.

Yeh, T. J., Ellison, L. T., and Ellison, R. G. (1962). Functional evaluation of the autotransplanted lung in the dog. Amer. Rev. resp. Dis., 86, 791. 